\title{
Three-Level Inverter Control Techniques: Design, Analysis, and Comparisons
}

\author{
Dan Selisteanu ${ }^{1}$, Monica Roman ${ }^{1, ~ *}$, Lucian Mandache ${ }^{2}$, Razvan Prejbeanu ${ }^{1,3}$, Sergiu Ivanov², \\ Alexandru Radu ${ }^{3}$ \\ ${ }^{1}$ Department of Automatic Control and Electronics, University of Craiova, \\ A. I. Cuza 13, 200585, Craiova, Romania \\ ${ }^{2}$ Faculty of Electrical Engineering, University of Craiova, \\ A. I. Cuza 13, 200585, Craiova, Romania \\ ${ }^{3} R \& D$ Electronic and Electrical Power Department, INDAELTRAC Ltd., \\ Bujorului 24, 200385, Craiova, Romania \\ monica.roman@edu.ucv.ro
}

\begin{abstract}
This work addresses the analysis and design of various Proportional-Integral-Derivative (PID) control techniques for a three-level inverter. Multilevel power converters are modern and basic elements of high-voltage electric drive and power supply systems. By using simulations and specific computer-aided design tools, the overall functional characteristics of multilevel converters, as well as the electrical demands of the components, can be accurately assessed to obtain an appropriate control solution. An innovative and detailed software model of a three-level inverter is developed and then used for the implementation of control techniques. Several tuning methods are used to tune PID controllers for two specific cases: the multilevel inverter with a linear load and with an asynchronous motor load, respectively. A detailed analysis and comparisons of the quality criteria and control performance are achieved. This analysis shows that the choice of controller type depends on the inverter load. For the linear load, proper results are obtained with a PI Nichols-tuned controller, and for the asynchronous load, with a PI controller tuned via a modified Hokushin method. The computer-aided design tools can be further used for the simulation of the equipment in various operating conditions, normal and fault, following all functional parameters.
\end{abstract}

Index Terms-Multilevel power converter; PID control; Induction motors; Simulation; Tuning methods.

\section{INTRODUCTION}

Multilevel power converters are essential elements of high-voltage electric drive and power supply systems. Failures of electronic power components mainly affect the reliability of these systems. Measurement and computing of limit conditions and operating regimes of power components is an important purpose in the definition and sizing of power supply networks.

Converters working at high operating voltages with direct alternating conversion and with thyristors are older and less efficient solutions compared to the other types of

Manuscript received 31 December, 2020; accepted 12 April, 2021.

This work was partially supported by European Regional Development Fund, Competitiveness Operational Program, project TISIPRO, Software solutions for multilevel inverter control with high energy efficiency, UCVINDAELTRAC, Grant No. P_40_416/105736, 2016-2021. conversion, mainly due to the limitations imposed by the parameters of power components. Nowadays, there are few applications in the industry that use these semiconductors in from DC to AC converters [1]-[3].

Direct-to-alternate Pulse Width Modulation (PWM) converters have a very wide range of applicability. They operate at high switching frequencies, use small passive filters, absorb quasi-sinusoidal currents from the network, and provide voltages close to the sinusoidal voltage to the loads. Modern and robust multilevel converters are in accordance with the current international standards [4], [5]. This is a very important aspect for industrial equipment.

The analysis and synthesis of the topology of multilevel converters are the fundamental elements in choosing the structural solution for converters that can operate at high voltage together with the optimal control solutions in terms of global energy efficiency. Multilevel structures are used mainly in the case of high-power converters when the working voltage is high, practically of $6 \mathrm{kV}$ [4], [6], [7]. The use of Insulated-Gate Bipolar Transistors (IGBTs) is more difficult for standard inverters in two levels, because the maximum working voltage for normal IGBTs is $6.5 \mathrm{kV}$ with a maximum voltage of $3.3 \mathrm{kV}$ in the intermediate circuit of the converters. For a supply voltage of $6 \mathrm{kV}$, it would be necessary to use components with a maximum working voltage of $12 \mathrm{kV}$.

Several control techniques were developed for multilevel converters (depending on the load), such as classical (including Proportional-Integral-Derivative (PID)) control techniques, model predictive control, nonlinear approaches, etc. [2], [8]-[10]. In the design process of an inverter, it is useful to simulate the behaviour of such converter for different loads and in different operational conditions.

In the present work, an innovative software model of a three-level inverter is built by using the Matlab/Simulink programming and development environment (a trademark of MatWorks, Inc., USA). The model is then used for the implementation of control techniques. Several tuning methods [11]-[14] are used to tune PID controllers for two specific cases: the three-level inverter with a linear load and 
with an asynchronous motor load, respectively.

A detailed analysis and comparisons of the quality criteria and control performance are also achieved. To be realistic and to prepare the implementation of an experimental system, several improvements of the software model are proposed, such as sine-wave passive LC filter at the inverter output (for linear load or power grid), high level of details for all blocks and connections, real switches with snubber elements, realistic implementation of the controllers, etc.

The paper is organized as follows. Section II deals with the presentation of the software model for the three-level inverter. Section III addresses basic issues about the PID control laws and their tuning. In Section IV, the quality criteria used for the analysis of the control performance of the inverter are described. Section V is dedicated to simulation results, discussion, and comparisons. Finally, in Section V, the conclusions of the paper are presented.

\section{INVERTER CONTROL SimUlation SCHEMES}

Power conversion systems with three-level inverters for $\mathrm{kV}$-level AC drives (typically $6 \mathrm{kV}$ ) are requested by the market for several industrial applications (high power water pumps, belt conveyors, rotating ovens, drilling systems, etc.). This context has led to a collaborative project intended to design and manufacture an experimental model of such a drive system as a starting point for a certified product and future mass production at INDAELTRAC. The present work aims to identify the most appropriate control techniques to be implemented, tested, validated, and authorized for this drive system. The experimental model is currently under construction, so that the experimental results will be presented in a future work. The present work is focused on the control strategies being organized gradually, starting with the case of a linear load connected to the inverter output. In the second stage, an asynchronous squirrel-cage motor is used as a load. The main parts of the developed simulation diagrams are the three-level power inverter in neutral-point clamped topology [3], [10], [15][19], together with the load (linear resistance-inductance load (RL) and asynchronous motor, respectively), the PWM command block, and the control loop.

They also contain additional elements for measuring, converting to other units, and displaying certain quantities of interest and, not least, to define the reference value(s) of the controlled variables. The controlled variable for the system with linear load is the output voltage under constant frequency (it is usually the main frequency of $50 \mathrm{~Hz}$ or 60 $\mathrm{Hz}$ ), while for the system supplying the induction motor, the motor speed is according to the strategy $V / f=$ constant [3], [10] to avoid the magnetic saturation of the motor.

In Fig. 1, the simulation diagram corresponding to the induction motor load is shown.

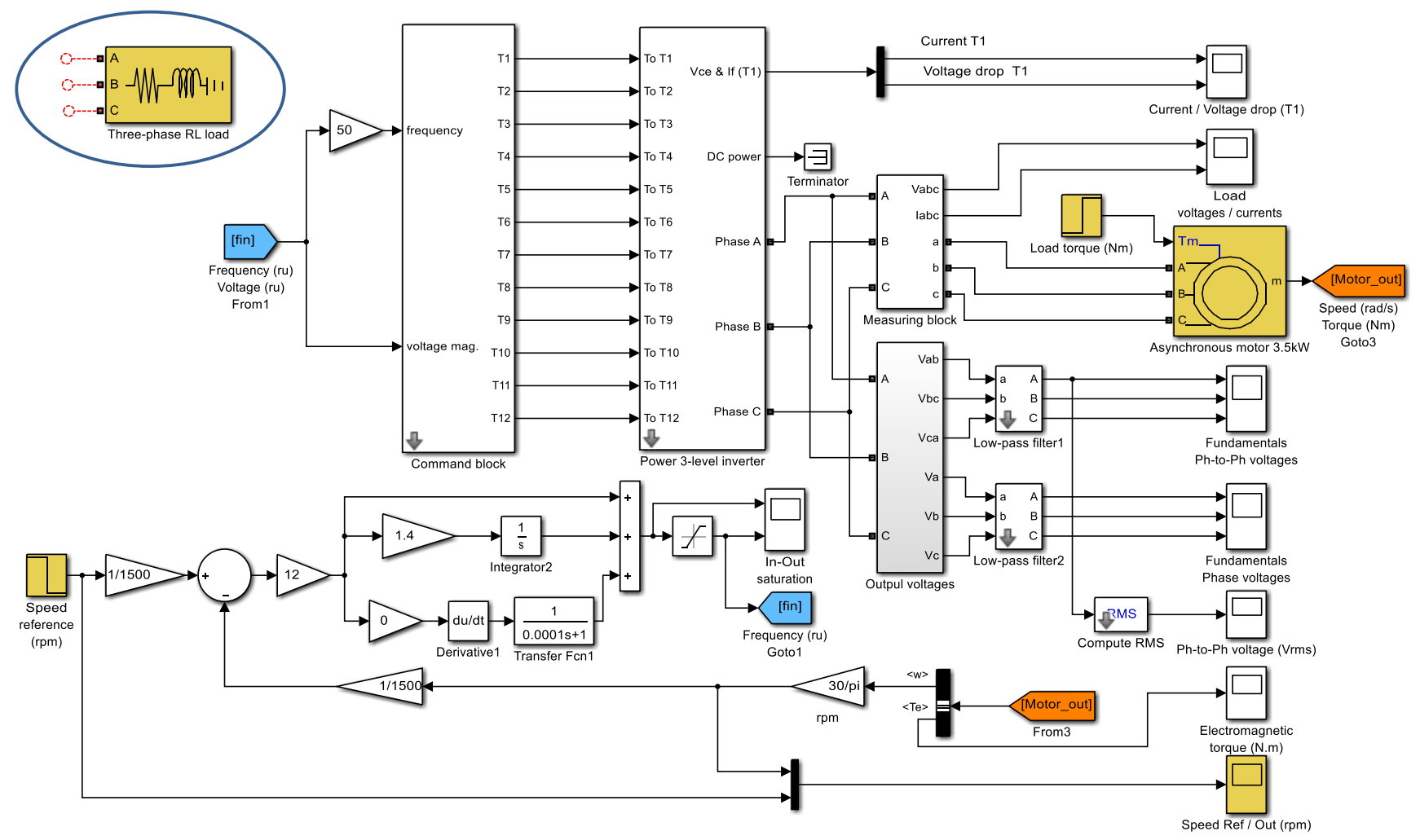

Fig. 1. Inverter simulation diagram with an asynchronous motor as load.

The control variable is the rotor speed converted to values of frequency; it is sent to the feedback loop and to a display to compare it with the reference. The control block used in the simulation diagram is versatile to allow testing any P, PI, or PID control laws. Its output variable is restricted within a physically possible domain by means of a saturation block, and then it is sent as an input variable to the command block. In this example, it is the frequency expressed in relative units related to $50 \mathrm{~Hz}$. Both input variables of the command block are expressed in relative units related to the nominal values (of the voltage and frequency), so that a sole command signal is enough to ensure the condition $V / f=$ constant. This command signal comes from the control block. 
The induction motor can be configured with constant or variable load torque defined as needed. Detailed diagrams of the PWM command block and the three-level power inverter are shown in Fig. 2(a) and Fig. 2(b), respectively. These blocks are linked via the command signals for the twelve IGBTs in the inverter legs. The power block contains an independent DC voltage source as an ideal DC link; this approach is preferred for reasons of simplicity, instead of supplying the system from the three-phase mains through a power rectifier. For easier use in various working conditions, the command block allows defining the carrier wave frequency as a parameter, while the power block allows choosing the DC voltage as a parameter.

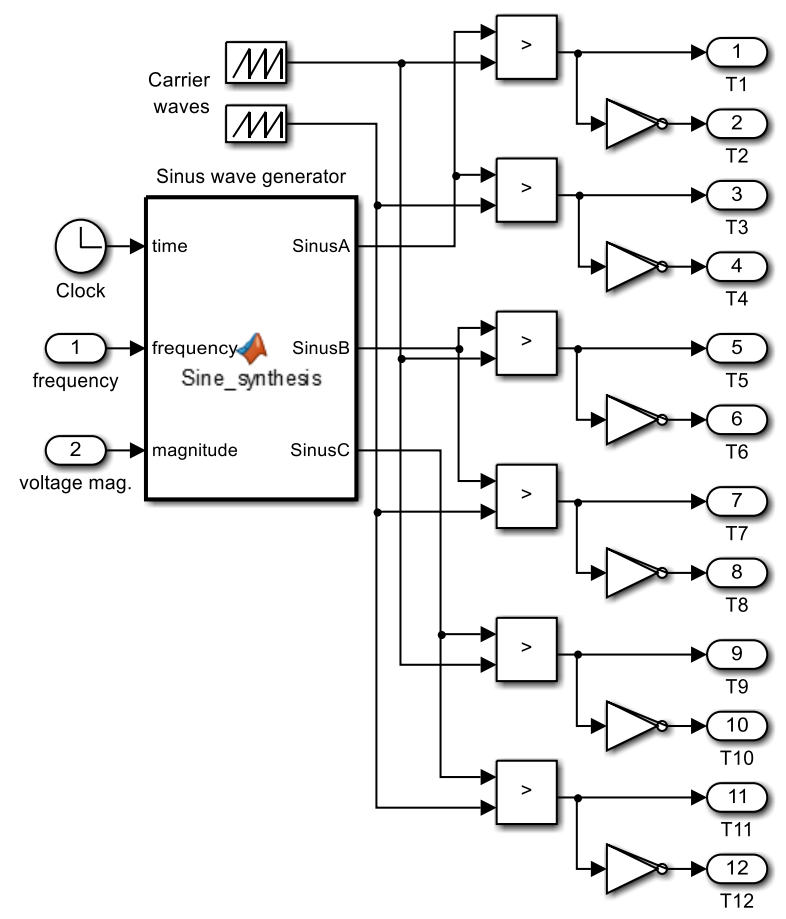

(a)

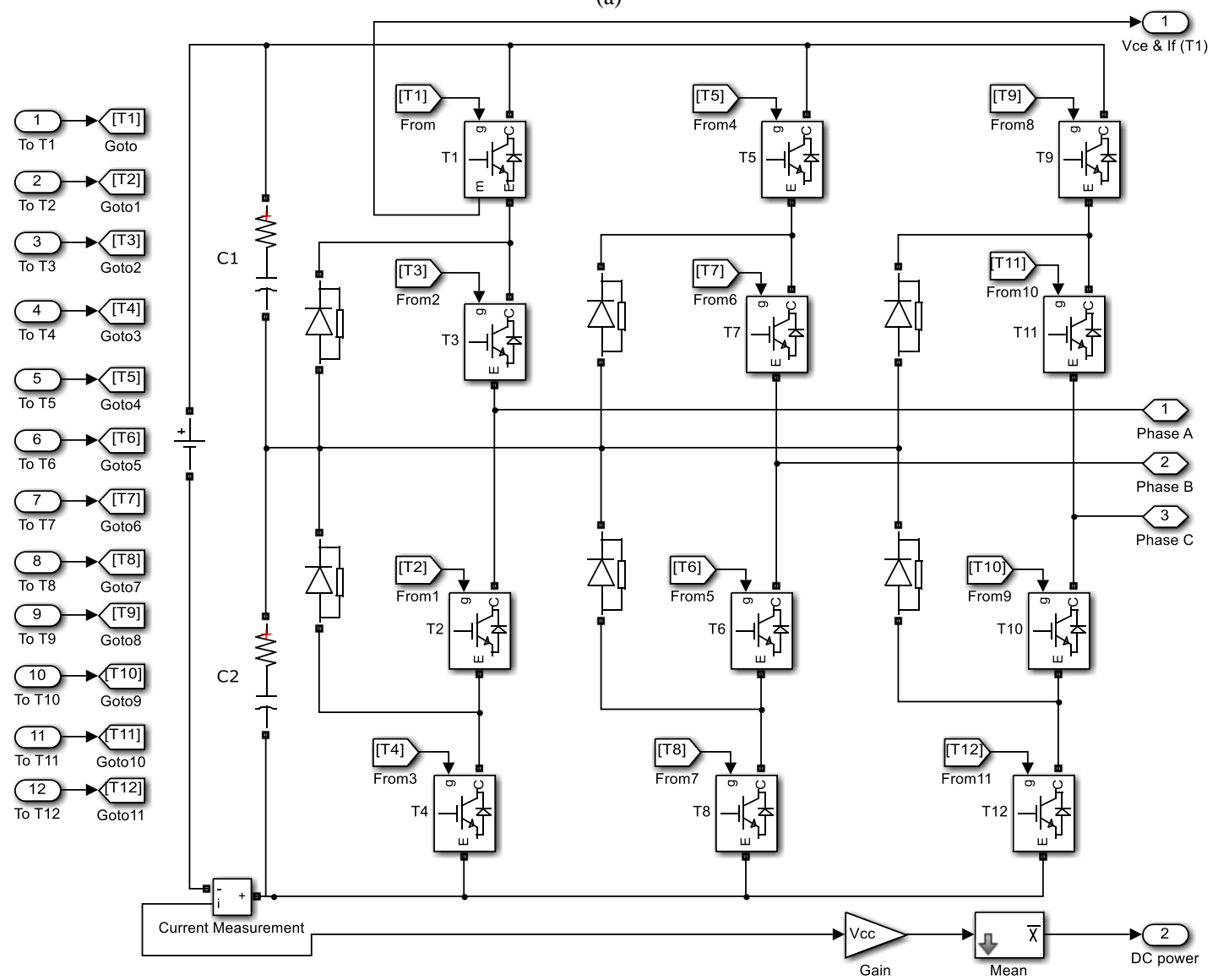

(b)

Fig. 2. Detailed diagrams: (a) PWM command block; (b) Three-level neutral-point clamped power inverter. 
The fundamental harmonic of the inverter output voltage in the time domain is obtained by means of a numerical lowpass filter, and its rms value is simply computed by a dedicated block. The effectiveness of the low-pass filter to extract the fundamental components of the voltages for the phase-to-phase voltage $V_{a b}$ is shown in Fig. 3.

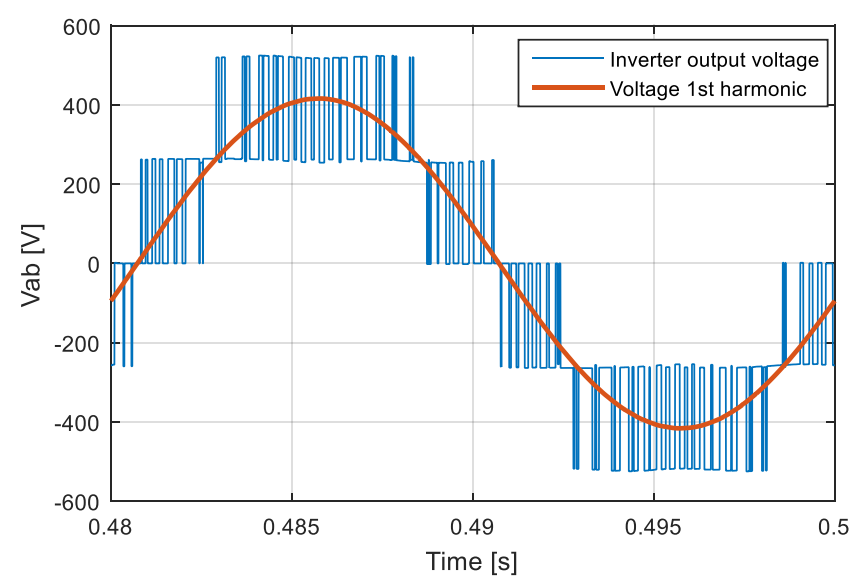

Fig. 3. Operation of the low-pass numerical filter to extract the fundamental component from the line-to-line voltage at the three-level inverter output.

As stated above, the control technics (which will be described in the next sections) were tested also on a similar system provided with a linear load.

It is designed to operate at a constant frequency, whose reference value is specified at the input of the command block in relative units related to the standard main frequency of $50 \mathrm{~Hz}$. The control variable in this case is the rms value of the fundamental harmonic of the phase-to-phase voltage at the load terminals. The related simulation diagram differs slightly from the one in Fig. 1: the motor is replaced with a RL linear load (shown in the upper left corner in Fig. 1); the control variable is taken from the RMS computing block mentioned above; the inputs of the command block are separated and only the voltage input is controlled. This system has been provided additionally with a sine-wave passive LC filter at the inverter output to guarantee a clean sine-wave voltage to the load terminals.

As a key point, unlike other similar achievements [3], [10], [18]-[20], the simulation model has been built for more realistic results concerning the control strategies and to allow an easier design and implementation of the expected experimental system. It should be noticed that all blocks and interconnections of the simulation model are deeply detailed, we paid attention to use real switches with proper snubber elements instead of ideal switches, we also used continuous time domain integration with variable time step instead of discrete time simulation. Relevant quantities are measured as in the experimental model.

\section{CONTROL LAWS DESIGN AND TUNING}

In the industrial practice of control, including the field of electric drive control, the so-called "PID control laws" or "PID controllers" have been imposed [11]-[13]. These controllers satisfy in most cases the technical requirements imposed on conventional control systems. Next, a succinct presentation about these control laws will be provided, including basic tuning procedures. If a mathematical model of a plant [21] is not available or it is uncertain (e.g., in the case of converters), it is possible to tune these controllers directly on the plant. The theory and practice of PID control are classic, the next descriptions being based on works, such as [11]-[14].

By using PID control laws within some (numeric) controllers, the dimensional value design of the control law is reduced to choosing the type of law and prescribing the values of the design parameters. It should be noted that various combinations of components can be used: P, I, D, PI, PD, and PID, in different variants. In general, it is not possible to precisely determine the effect of each component on the quality of the control system, as they depend on the structure of the system and on the plant dynamics.

To simulate the inverter control system, a complex model is implemented in the Matlab/Simulink environment (Fig. 1). The inverter control schemes are provided with classical PID controllers emulated in the software model in Fig. 1. The control law design parameters are tuned by using several tuning procedures. Next, the transfer functions of the control laws and some design parameters used in the simulation will be shortly presented.

$P$ controller. If this law is regarded as a non-dynamical object, then the transfer function is $H(s)=K_{P}$. The proportional gain $K_{P}$ can be experimentally computed as the ratio between output and input variations in the steady state.

By denoting by $D_{u}$ the input range and by $D_{y}$ the output range, the relative or percentage proportional gain can be defined as the ratio between the percentage output variation and the percentage input variation (in steady state)

$$
K_{P}^{r e l}=\frac{\Delta y \%(\infty)}{\Delta u \%(\infty)}, K_{P}^{r e l}=\frac{D_{u}}{D_{y}} K_{P} .
$$

Definition 1. The proportionality band denoted $P B \%$ means a measure of the amplification of a system expressed by the percentage of the input range, which determines at the output a value of $100 \%$ of its domain

$$
P B \%=\frac{100}{K_{P}^{r e l}}=\frac{100}{K_{P}} \times \frac{D_{y}}{D_{u}} .
$$

Integral control law. The transfer function is given by

$$
H(s)=\frac{K_{P}}{T_{i}} \times \frac{1}{s}=K_{I} \times \frac{1}{s},
$$

where $T_{i}$ is the integral time constant (reset time), and $K_{I}$ is the integral gain.

PI control law. The transfer function can be expressed as

$$
H(s)=K_{P}\left(1+\frac{1}{\mathrm{~T}_{\mathrm{i}} s}\right)=K_{P}+\frac{K_{I}}{s} .
$$

PD control law. The transfer function of a physically 
implementable PD controller is given by

$$
H(s)=K_{P} \frac{T_{d} s+1}{T_{\gamma} s+1} .
$$

where $T_{d}$ is the derivative time constant (rate time), and $T_{\gamma}$ is a parasitic time constant, often defined with respect to the rate time, as $T_{d} / n . K_{D}=K_{P} T_{d}$ is the derivative gain.

PID controller. Depending on the physical realization, several structures of PID (physically implementable) control laws can be obtained. One of these is the parallel connection between I and PD controllers with the transfer function

$$
H(s)=K_{P}\left(\frac{1}{T_{i} s}+\frac{T_{d} s+1}{T_{\gamma} s+1}\right) .
$$

Controller tuning. To find the optimal values of the design parameters of PID control laws, several types of tuning algorithms (procedures or methods) can be used with respect to different criteria. Thus, plant models with or without dead time of order 1 or 2, but also of a higher order, can be considered to apply tuning methods, such as Nichols, Oppelt, Chien-Hrones-Reswick, Kopelovici, Cohen and Coon, Pessen, Haazebroeck-Waerden, etc. [11], [13], [14]. Of great importance for inverter control are the so-called "heuristic tuning methods", which can be applied without the knowledge of the plant model. These methods, such as Ziegler-Nichols, impose the tuning of the control design parameters by running the closed loop system.

Nichols tuning method. First, the limit values $K_{P \lim }$ and $T_{\text {lim }}$ are obtained. For this purpose, when $T_{i}=\infty$ and $T_{d}=0$, the proportional gain is increased until permanent oscillations appear at the system output. This value of $K_{P}$ is $K_{P \lim }$ (i.e., a certain value of $P B_{\lim } \%$ ) and $T_{\lim }$ is the oscillation period [11]-[14]. Then, the tuning relations presented in Table I can be used.

Ziegler-Nichols method. It is a well-known tuning procedure based on the square integral criterion for a step disturbance applied to the output [11]-[14].

Hokushin tuning method. This method uses successive adjustments of the design parameters [11]-[14]. The tuning procedures are sketched in Table II.

TABLE I. TUNING RELATIONS - NICHOLS METHOD.

\begin{tabular}{|c|c|c|c|c|}
\hline & $\boldsymbol{K}_{\boldsymbol{P}}$ & $\boldsymbol{P B} \%$ & $\boldsymbol{T}_{\boldsymbol{i}}$ & $\boldsymbol{T}_{\boldsymbol{d}}$ \\
\hline $\begin{array}{c}\mathbf{P} \\
\text { controller }\end{array}$ & $0.50 \times K_{P \lim }$ & $2 \times P B_{\lim } \%$ & - & - \\
\hline $\begin{array}{c}\text { PI } \\
\text { controller }\end{array}$ & $0.45 \times K_{P \lim }$ & $2.22 \times P B_{\lim } \%$ & $0.85 \times T_{\lim }$ & - \\
\hline $\begin{array}{c}\text { PID } \\
\text { controller }\end{array}$ & $0.75 \times K_{P \lim }$ & $1.33 \times P B_{\lim } \%$ & $0.6 \times T_{\lim }$ & $0.1 \times T_{\lim }$ \\
\hline
\end{tabular}

TABLE II. TUNING PROCEDURES - HOKUSHIN METHOD

\begin{tabular}{|l|l|}
\hline \multicolumn{1}{|c|}{ PI controller } & \multicolumn{1}{|c|}{ PID controller } \\
\hline$-P B \%$ and $T_{i}$ are set & $-P B \%$ and $T_{i}$ are set to maximum \\
to maximum values; & values and $T_{d}$ to minimum; \\
$-P B \%$ is decreased & $-P B \%$ is decreased until the \\
until the oscillations & oscillations appear; \\
appear; & $-T_{d}$ is increased until the oscillations \\
$-P B \%$ is increased & disappear; \\
such that the &
\end{tabular}

\begin{tabular}{|l|l|}
\hline \multicolumn{1}{|c|}{ PI controller } & \multicolumn{1}{c|}{ PID controller } \\
\hline $\begin{array}{l}\text { oscillations disappear } \\
\text { with a small reserve; }\end{array}$ & $\begin{array}{l}-P B \% \text { is decreased again. When the } \\
\text { oscillations reappear, } T_{d} \text { is increased }\end{array}$ \\
$-T_{i}$ is decreased until & $\begin{array}{l}\text { again until their disappearance; } \\
\text { the oscillations }\end{array}$ \\
appear; & $\begin{array}{l}\text { - The procedure is repeated until the } \\
\text { oscillations cannot be distinguished }\end{array}$ \\
$-T_{i}$ is increased until & when $T_{d}$ is increased. Then $P B \%$ is a \\
the oscillations & $\begin{array}{l}\text { little increased to have a reserve; } \\
\text { disappear with a small }\end{array}$ \\
reserve; & $-T_{i}$ is decreased until some slow \\
- The values of $P B \%$ & oscillations appear; \\
and thus obtained & $-T_{i}$ is increased until the oscillations \\
are the final tuning & vanish, and after that a value for $T_{i}$ is \\
values. & set such as a small reserve to exist. \\
\hline
\end{tabular}

Remark 1. Some of the aforementioned tuning methods can be implemented in an automatic way if the SISO Design Tool (Matlab) is used. This tool possesses the so-called "automated tuning option".

\section{QuAlity CRITERIA AND PERFORMANCES FOR CONTROL SYSTEMS}

To evaluate the control performance of the three-level inverter control schemes, some quality criteria will be used. Next, fundamental notions concerning the quality criteria and control performance are presented.

Definition 2. A quality criterion of a system is a measure of the quality of the evolution of this system.

Definition 3. The performance of a system with respect to a quality criterion $Q C_{i}$ is an inequality (or equality) relationship $P_{i}$ imposed to the quality criterion.

The performance can be formally expressed as a predicate

$$
P_{i}: " Q C_{i} \leq Q C_{\text {iimp }} \text { " or } P_{i}: " Q C_{i} \geq Q C_{\text {iimp }} \text { ". }
$$

The quality criteria can be classified (in a non-exhaustive way) as in [12], [13]:

- Global quality criteria, which measure (evaluate) the global behaviour of the system in finite or infinite time (the so-called "integral criteria");

- Local (or technical) quality criteria, which measure some attributes of the system response when typical inputs are applied (impulse, step, ramp, and harmonic signals).

The evolution attributes frequently used in control systems, expressed as local quality criteria, can evaluate:

1. The steady state system precision: the steady state errors due to the setpoint variation or due to the variation of a disturbance $\varepsilon_{\infty}, \varepsilon_{p \infty}$; the general gain coefficients.

2 . The stability reserve of a system in dynamic regime: overshoot, damping factor, phase margin, gain margin, etc.

3. The speed of the system: settling time $t_{r}$, rise time $t_{c}$, frequency band $\omega_{b}$, etc.

These quality criteria define the desired form of the response of a system to be synthesized, a response, which is determined by the variation of the prescribed variable and/or by the variation of one or certain disturbances.

The definitions and the derived theory concerning the quality criteria and the performance of the control systems 
are classical, the descriptions used in this work being based on works, such as [12]-[14], [22].

\section{A. Global Quality Criteria}

Global quality criteria are usually expressed by integrals (in the case of continuous systems) or by summations (for discrete systems). The most used are the square criteria, because they allow for analytical solutions for a wide range of systems. The performance is defined by the condition that these integrals (sums) have a minimum value in some problems or a maximum value in other problems. By specifying the overall quality criteria, the purpose of minimising (maximising) it is understood. The performance $P$ defines the synthesis problem $P^{\prime}=\{P\}$, which is also called the "optimization problem". The general form of the integral criteria for systems with the input $u$ and the state $x$ is as follows (for continuous and discrete systems, respectively):

$$
\begin{gathered}
J=\int_{0}^{T} L(x, u, t) d t, T=\text { finite } \text { or } T=\infty \\
J=\sum_{k=0}^{N} L(x, u, k), N=\text { finite or } N=\infty
\end{gathered}
$$

The function $L($.$) is called the "objective function". In a$ minimization problem, $L($.) expresses the penalty at time $t$ (step $k$ for discrete systems), and in a maximisation problem, the gain at time $t$ (step $k$ ). The difficult aspect in using integral criteria to solve the control design is how to define the objective function. This objective function transposes the system desired behaviour into a concise mathematical form.

Next, some of the integral criteria, which are commonly used for the assessment of the quality of continuous control systems, will be succinctly defined by considering $\varepsilon$ as the system error (the difference between reference and output).

Integral Time Absolute Error (ITAE):

$$
\text { ITAE }=\int_{0}^{T} t|\varepsilon(t)| d t, T=\text { finite or } T=\infty .
$$

Integral Square Error (ISE):

$$
I S E=\int_{0}^{T} \varepsilon^{2}(t) d t, T=\text { finite or } T=\infty .
$$

Integral Absolute Error (IAE):

$$
I A E=\int_{0}^{T}|\varepsilon(t)| d t, T=\text { finite or } T=\infty .
$$

Integral Time Square Error (ITSE):

$$
I S E=\int_{0}^{T} t \varepsilon^{2}(t) d t, T=\text { finite or } T=\infty .
$$

The significance of these integral criteria depends on the interpretation of the system error evolution. For example, ISE will penalize large errors more than small ones. Thus, the control systems designed to minimise the ISE criterion will tend to eliminate large errors very quickly, but will tolerate small errors that persist over time. This type of design can lead to fast responses, but with persistent oscillations of low amplitude. In the case of IAE, a slower response is usually obtained than in the case of ISE, but with more attenuated oscillations. Because ITAE integrates the absolute error multiplied over time, it has the effect of weighting the persistent errors more than those in the transient regime. Hence, a control design based on the ITAE specification will produce a response that will have fewer oscillations, but will be slow in the transient regime. Sometimes, the integral criteria have been called "academic" because they can be applied with difficulty in practice. The local criteria, which are not so accurate or global, are often preferred since they are easier to calculate and apply in practice.

\section{B. Local Quality Criteria}

The local criteria used to evaluate the performance of the inverter control system are briefly presented in this section. The basic definitions of local quality criteria refer to all categories of control systems. The criteria clearly depend on the type (shape) of the input signal, but not on the parameters that differentiate signals of the same type. More generally, input signals and responses are defined by variations of their values in a permanent regime [13].

Quality criteria for the assessment of system accuracy. The most used criteria are the general gain coefficients and the steady state errors.

The general gain coefficients are defined in steady state by using the open loop transfer function $H^{d}(s)=H_{R}(s) \times H_{F}(s)$. The structure of the control system is presented in Fig. 4.

Definition 4. The position gain coefficient $G_{P}$ is the ratio between the output variation and error variation (compared to their values in a previous steady state) for $t \rightarrow \infty$ :

$$
G_{P}=\lim _{t \rightarrow \infty} \frac{y(t)}{\varepsilon(t)}=\frac{y(\infty)}{\varepsilon(\infty)} .
$$

For linear systems,

$$
G_{P}=\lim _{s \rightarrow 0} H^{d}(s) .
$$

Steady state error with respect to the prescribed variable (reference) is defined in the steady state regime.

Definition 5. The position steady state error with respect to the prescribed variable, denoted $\varepsilon_{0 \infty}$, can be defined as the variation of the system error due to the step variation of the prescribed variable in steady state.

The standard evolution used in the definition and measure of the steady state error is presented in Fig. 5. The performance is imposed via the inequality $\varepsilon_{0 \infty} \leq \varepsilon_{0 \infty i m p}$. Due to the fact that $\varepsilon_{0 \infty}$ depends on the value of the step input $V_{0}$, to obtain a criterion which depends only on the system structure, the relative steady state error can be defined as

$$
\varepsilon_{0 \infty}^{r e l}=\frac{\varepsilon_{0 \infty}}{V_{0}}=\frac{1}{1+G_{P}} .
$$


The performance in this case is imposed via the inequality $\varepsilon_{0 \infty}^{r e l} \leq \varepsilon_{0 \infty, i m p}^{r e l} \Leftrightarrow G_{P} \geq G_{P, \text { imp }}$. As it is well known, the steady state error is zero if and only if the position gain is infinite $\varepsilon_{0 \infty}^{r e l}=0 \Leftrightarrow G_{P}=\infty$, i.e., the open loop transfer function has at least a pole in the complex plane origin.

Remark 2. Other steady state errors can be defined as well [11]-[13], e.g., the speed steady state error with respect to the imposed variable, the steady state error with respect to a disturbance, etc.

Criteria for the assessment of system quality in the transient regime. These criteria usually measure the stability reserve and the speed of the system. A possible classification of these is: criteria defined on the transient regime triggered by the step variation of the prescribed variable (setpoint) and criteria defined on the transient regime triggered by the step variation of a disturbance.

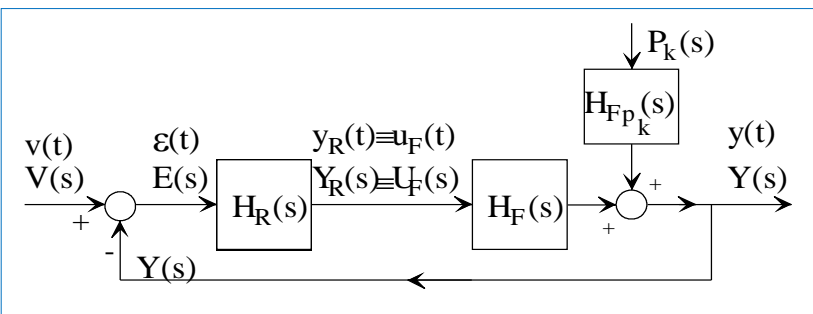

Fig. 4. The classical block scheme of a linear control system, where $H_{R}$ is the controller transfer function, $H_{F}$ is the process transfer function, and $H_{F p k}$ is the process transfer function with respect to the disturbance $p_{k}$.

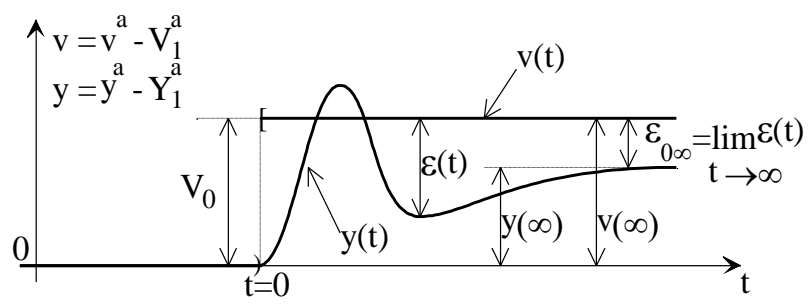

Fig. 5. The position steady state error - standard representation $(v-$ the setpoint, $y$ - the system output).

We will analyse the first category.

The response of the system at a step input variation can be represented as in Fig. 6, where we have $t=t-t_{0}^{a}$, $v(t)=v^{a}\left(t+t_{0}^{a}\right)-v_{s t}^{a}\left(t_{0}^{a}\right)$, and $y(t)=y^{a}\left(t+t_{0}^{a}\right)-y_{s t}^{a}\left(t_{0}^{a}\right)$.

Several criteria can be defined [11]-[13], but only some of the most used will be presented.

The (maximum) overshoot $\sigma$ is one of the most used quality criteria for the assessment of the transient regime of a control system.

Definition 6. The overshoot is the maximum exceedance by the output of its steady state value resulting from the transient regime caused by the step variation of the reference (see Fig. 6). The overshoot expresses the system precision, but is also considered a measure of the stability reserve. It can be defined by the relationship

$$
\sigma=\max _{j \in J}\left|\sigma_{j}\right|, J=\left\{j \in N^{*}, \sigma_{j} \times y(\infty)>0\right\} .
$$

Other specific criteria and the consequent performances are the relative overshoot $\sigma^{r e l}=\sigma / y(\infty), \quad \sigma^{r e l} \leq \sigma_{i m p}^{r e l}$ and percentage overshoot $\sigma \%=\sigma_{r e l} \times 100, \sigma \% \leq \sigma \%$ imp .

Definition 7 . The rise time $t_{c}$ represents the time interval during which the output changes from the value $0.05 \mathrm{y}(\infty)$ to the value $0.95 \mathrm{y}(\infty)$, in the transient regime caused by the step variation of the reference (see Fig. 6). The performance for this criterion is defined by using the inequality $t_{c} \leq t_{\text {cimp }}$.

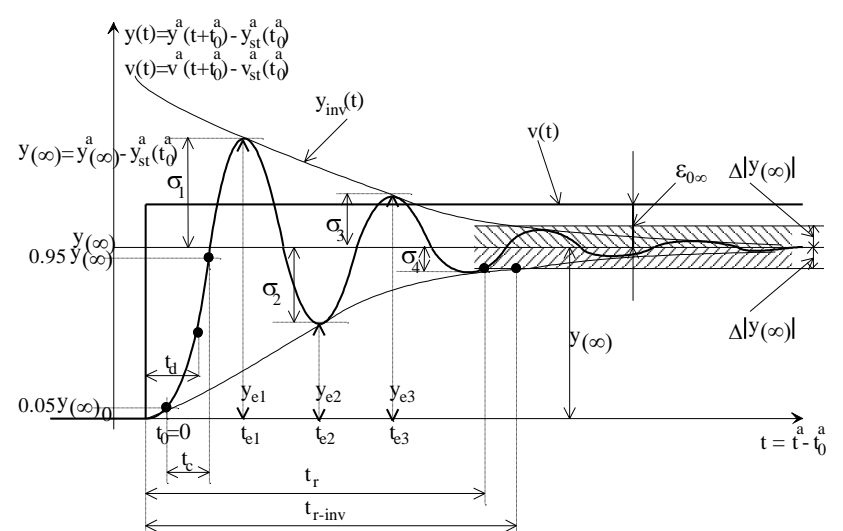

Fig. 6. The definition of some quality criteria on the system response obtained for the step variation of the imposed variable (reference) [13].

Remark 3. These criteria, including other criteria, such as the stelling time ( $t_{r}$ in Fig. 6), but also the so-called "harmonic criteria" (e.g., phase and gain margins), can be easily computed by using specialized software packages, such as Matlab (SISO Tool) [23]-[25].

\section{Simulation Results AND COMPARISONS}

\section{A. Control Structures, Tuning, and System Simulation}

To control the multilevel inverter, several schemes with P, PI, and PID controllers were investigated, and different practical tuning methods were used. As regards the force schemes, to best reproduce the operation under real conditions, both an inductive linear load and an asynchronous motor (with squirrel-cage rotor) were used. In the case of linear load, the voltage control at the inverter output is considered, and in the case of asynchronous motor load, the speed regulation is achieved by using the mixed voltage-frequency control ( $V / f=$ constant $)$ [26].

In both cases, simulation schemes were designed and implemented in Simulink, their open loop operation being studied for model validation. The simulation diagrams were presented in Section II, describing the power switching circuit, the three-level voltage inverter command structure, and the loads (linear three-phase RL, respectively, asynchronous motor), accompanied by the closed loop control algorithms. In addition, low-pass digital filters were also implemented to extract the fundamental harmonics of the phase and line voltages from the inverter output [27]. The measuring blocks for load voltages and currents, for phase and line voltages, and for all other interest variables were also developed.

Several quality criteria and control performance are computed for two cases: 
- Control performance for the multilevel inverter with RL load (the control goal is to regulate the effective voltage at the inverter output);

- Control performance for the multilevel inverter with asynchronous motor load (the control goal is to regulate the angular speed of the motor).

To assess the control performance, the quality criteria described in Section IV are used. Thus, local criteria (such as overshoot, steady state error, position gain, rise time) and global criteria are computed and the control structures with different controllers are compared.

\section{B. Performance Analysis - Inverter with Linear Load}

The simulation scheme of the control system is presented in Fig. 1. The voltage feedback loop is provided with a real PID regulator, which can be configured by setting the design parameters to obtain P, PI, PD, and PID control laws. The simulation targets an intermediate circuit voltage of $300 \mathrm{~V}$, which can be achieved by recovering a single-phase voltage of $230 \mathrm{~V}$ at a $4 \mathrm{kHz}$ carrier signal frequency, commonly used in similar applications with the frequency of the useful signal $50 \mathrm{~Hz}$ and an amplitude modulation factor of 0.8 .

The voltage feedback is taken from the output of the effective value calculation block. The feedback signal is normalized by reference to the maximum voltage value that the inverter can provide (for a unit amplitude of the modulation factor).

The prescribed value is specified by means of a step source block. The error signal is applied to the controller's input. At the controller output, a saturation block was provided to limit the normalized frequency value applied to the input of the inverter command block. The frequency is normalized with respect to the reference value of $50 \mathrm{~Hz}$.

Different types of regulators were implemented, and their parameters were tuned by using practical methods. Nichols, Ziegler-Nichols, and Hokushin methods have been tested, these techniques being suitable since a complete mathematical model of the plant is not available.

Next, the results obtained with several control structures tuned with different methods are succinctly presented. More precisely, the type of regulator, the tuning method, the design parameters, as well as the output and reference evolution, are presented.

The computed quality criteria for different control structures and parameters are also summarized. It has been observed that the introduction of a derivative component leads to an increase of the response oscillations (this remark is also valid for asynchronous motor loads). Tables III and IV show the quality criteria computed as shown in Section IV.

$P$ controller, Nichols tuning method, $K_{P}=2.1$. Figure 7 shows the output profile and the reference (setpoint). It can be noticed that the controller does not provide a null (or almost null) steady state error. Small oscillations of the output are observed in the steady state zone.

$P I$ controller, Nichols tuning method, $K_{P}=1.8$; $T_{i}=0.025 ; K_{I}=K_{P} / T_{i}=72$. From the qualitative analysis of the evolution in Fig. 8, it results that the PI controller leads to a steady state error close to zero, i.e., precision in the stationary regime. Moreover, the closed loop system response does not have oscillations. However, the overshoot is quite high. Although in terms of rise time the performance seems similar to the previous case, the settling time is somewhat longer.

PI control law, Ziegler-Nichols tuning method, $K_{P}=1.8$; $T_{i}=0.1 ; K_{I}=K_{P} / T_{i}=18$. From the analysis of the evolution in Fig. 9, it is noted that the PI controller leads to a steady state error close to zero, but greater than in the previous case (see also Table III). Slight oscillations of the output are present during the transient regime. The rise time is similar to that obtained in other cases.

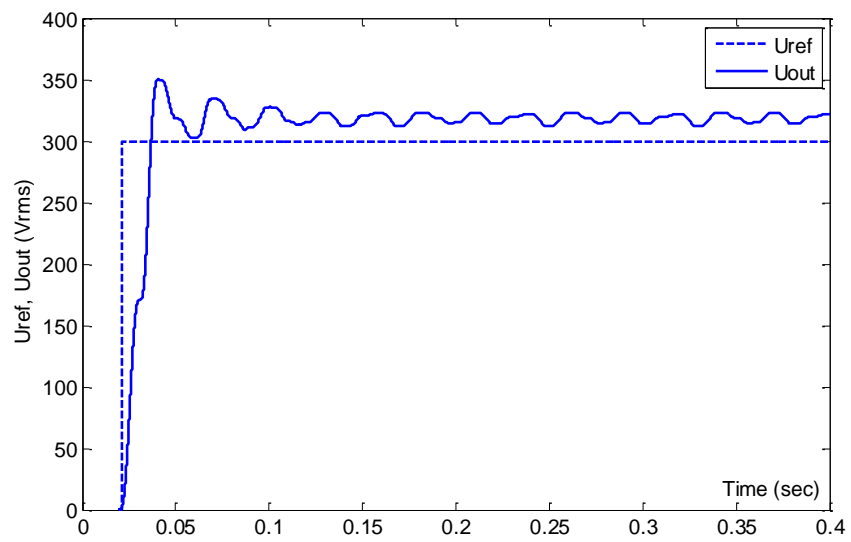

Fig. 7. Evolution of output vs. prescribed variable, $\mathrm{P}$ controller, Nichols tuning method.

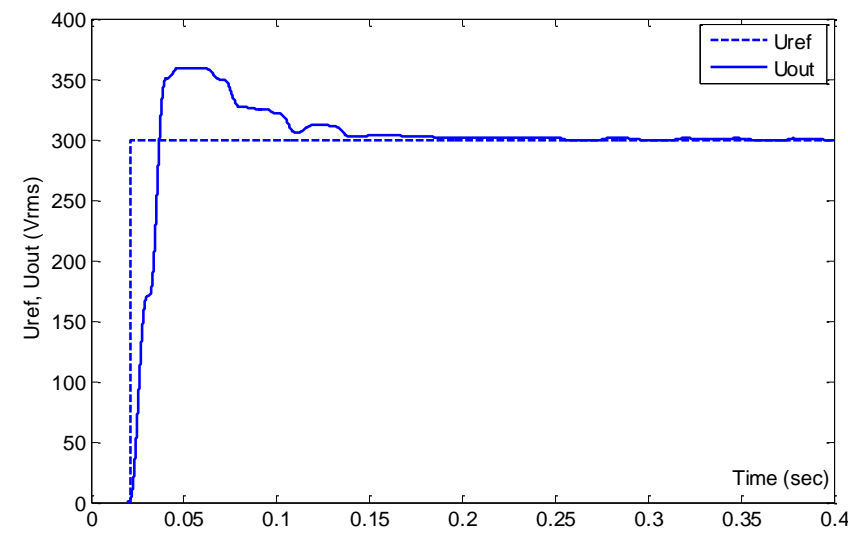

Fig. 8. Output and setpoint, PI control law, Nichols tuning method.

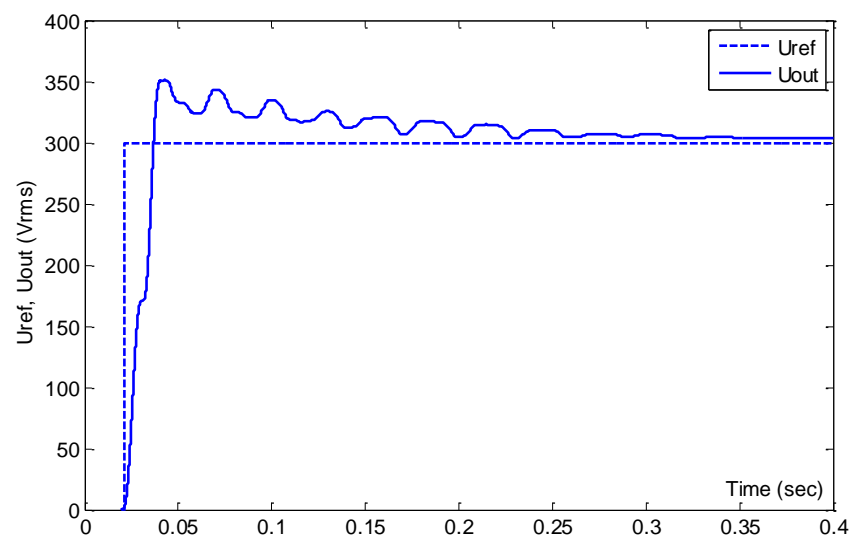

Fig. 9. Output and reference profiles, PI controller, Ziegler-Nichols tuning method. 


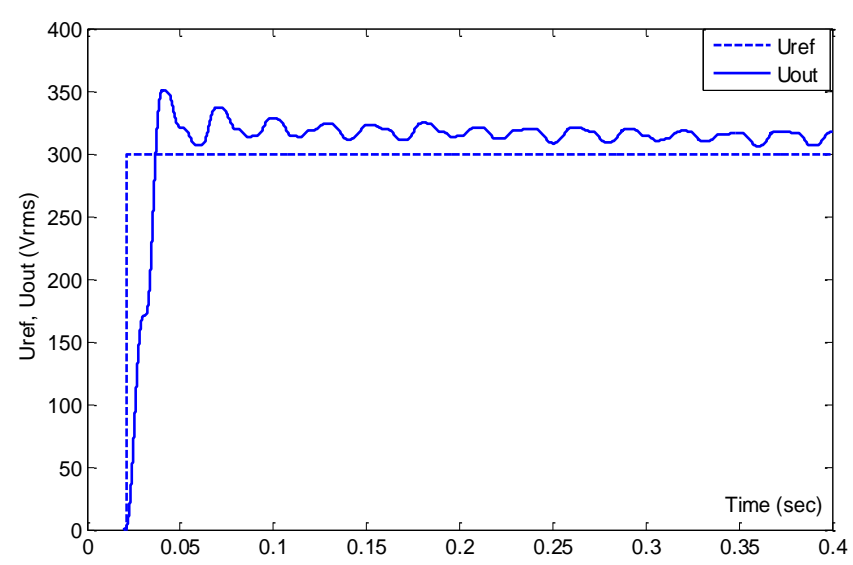

Fig. 10. Output vs. setpoint, PI controller, Hokushin tuning method.

TABLE III. LOCAL CRITERIA AND CONTROL PERFORMANCE INVERTER WITH LINEAR LOAD.

\begin{tabular}{|c|c|c|c|c|}
\hline & $\begin{array}{c}\text { Steady } \\
\text { state error } \\
\boldsymbol{\varepsilon}_{0_{0}}^{\text {rel }}\end{array}$ & $\begin{array}{c}\text { Position } \\
\text { gain } \\
\boldsymbol{G}_{\boldsymbol{p}}\end{array}$ & $\begin{array}{c}\text { Overshoot } \\
\boldsymbol{\sigma} \%\end{array}$ & $\begin{array}{c}\text { Rise } \\
\text { time } \\
\boldsymbol{t}_{\boldsymbol{c}}(\mathbf{s})\end{array}$ \\
\hline $\begin{array}{c}\text { P controller, } \\
\text { Nichols }\end{array}$ & 0.0715 & 12.9841 & $16.7 \%$ & 0.0136 \\
\hline $\begin{array}{c}\text { PI controller, } \\
\text { Nichols }\end{array}$ & 0.0021 & 466.8616 & $19.7 \%$ & 0.0137 \\
\hline $\begin{array}{c}\text { PI controller, } \\
\text { Ziegler-Nichols }\end{array}$ & 0.0109 & 90.9380 & $17.05 \%$ & 0.0137 \\
\hline $\begin{array}{c}\text { PI controller, } \\
\text { Hokushin }\end{array}$ & 0.0576 & 16.3747 & $16.78 \%$ & 0.0139 \\
\hline
\end{tabular}

TABLE IV. GLOBAL CRITERIA AND CONTROL PERFORMANCE INVERTER WITH LINEAR LOAD.

\begin{tabular}{|c|c|c|c|c|}
\hline & ITAE & ISE & IAE & ITSE \\
\hline $\begin{array}{c}\text { P controller, } \\
\text { Nichols }\end{array}$ & 1.5403 & 659.4951 & 9.4636 & 41.8483 \\
\hline $\begin{array}{c}\text { PI controller, } \\
\text { Nichols }\end{array}$ & 0.3634 & 648.4114 & 6.0043 & 21.5115 \\
\hline $\begin{array}{c}\text { PI controller, } \\
\text { Ziegler-Nichols }\end{array}$ & 0.7942 & 627.5173 & 7.5650 & 24.6327 \\
\hline $\begin{array}{c}\text { PI controller, } \\
\text { Hokushin }\end{array}$ & 1.3180 & 642.1732 & 8.8947 & 34.8700 \\
\hline
\end{tabular}

PI controller, Hokushin tuning method, $K_{P}=2.1$; $T_{i}=0.5 ; K_{I}=K_{P} / T_{i}=4.2$. In Fig. 10, the profiles of the output and prescribed variable are shown.

The steady state error is greater than in other cases of PI controllers, but lower than in the $\mathrm{P}$ regulator case (which is justified by the presence of the integrator in the PI law). The overshoot, however, is slightly smaller than the previous PI regulators. The response of the closed loop system is characterized by slight oscillations, both in the transient mode and near stationary regime.

In addition, PID controllers were tuned by using the Nichols $\quad\left(K_{p}=3 ; T_{i}=0.018\right.$; $K_{I}=K_{p} / T_{i}=166 ; T_{d}=0.003$;

$\left.K_{D}=K_{p} T_{d}=0.009 ; T_{\gamma}=0.0001\right)$ and the Ziegler-Nichols method $\left(K_{p}=1.8 ; T_{i}=0.2 ; \quad K_{I}=K_{p} / T_{i}=9 ; T_{d}=0.0003\right.$; $\left.K_{D}=K_{p} T_{d}=0.00054 ; T_{\gamma}=0.0001\right)$. However, the results in the case of PID controllers are not proper due to the high oscillations of the response.

Remark 4. It should be mentioned that the profiles of the fundamental harmonic were also analysed for each simulation to assess the distortions that occur for different control structures.

Remark 5. The performances that should be satisfied by the control system can be expressed by inequalities, such as $\varepsilon_{0 \infty}^{r e l} \leq \varepsilon_{0 \infty, i m p}^{r e l} \Leftrightarrow G_{P} \geq G_{P, i m p}, \quad \sigma \% \leq \sigma \%_{\text {imp }}, \quad$ and $t_{\mathrm{c}} \leq t_{\text {cimp }}$, already discussed in the previous section.

From the analysis of the local quality criteria presented in Table III, it can be concluded that the Nichols-tuned PI controller enables the best accuracy performance, and the PI tuned by Ziegler-Nichols achieves satisfactory accuracy performance under the conditions of lower overshoot.

Table IV shows the global criteria values for the linear load inverter control system. The advantage of these criteria is that they capture the behaviour of the error throughout the evolution range. From the analysis of the data presented in Table IV, it is noted that the performance of ITAE, IAE, and ITSE is best for the PI regulator tuned via Nichols method, and in the case of ISE, the best value is obtained for the PI controller tuned by using Ziegler-Nichols method. The Hokushin tuning-based PI controller also has a good value for the ISE criterion.

\section{Performance Analysis - Inverter with Asynchronous Motor Load}

The control system simulation scheme for the inverter with an asynchronous motor as a load is shown in Fig. 1, but with the linear load replaced by a simulation block corresponding to the asynchronous motor (see Section II). The rotational speed feedback loop is provided with a PI controller. The linear load from the previous case has been replaced by an asynchronous short-circuit rotor motor. The scheme allows the motor speed to be changed by simultaneously adjusting the voltage and frequency, such that the $V / f$ ratio to be constant.

The input variable is the synchronization angular speed, which is specified by using a step source block. It is configured for a start from $0 \mathrm{rpm}$ to $800 \mathrm{rpm}$ and a speed increase from $800 \mathrm{rpm}$ to $1200 \mathrm{rpm}$. The speed feedback taken from the measurement port in $\mathrm{rad} / \mathrm{s}$ is converted to rpm for display purposes, then is normalized with respect to the motor synchronism speed. The prescribed value is also normalized, and the error signal is applied to the controller provided with an output saturation block. The normalized frequency and voltage signals ensure that the $V / f$ ratio is constant and is applied to the control block input.

Different types of controllers were implemented, and their parameters were tuned by using practical methods: Nichols, Ziegler-Nichols, and Hokushin. Next, the performance of different $\mathrm{P}$ and PI control structures is analysed (the derivative component leads to an increased oscillatory response). The controller type, the tuning method, the design parameters, and the time evolution of output and reference are presented. Tables V and VI show the quality criteria, similar to the case of the linear load. It should be mentioned that a significantly faster response of the closed loop system with the comparison to the open loop operation is observed.

$P$ controller, Nichols tuning, $K_{P}=190$. Figure 11 presents the output and reference variable (rotor speed). Even if the $\mathrm{P}$ controller cannot provide a null steady state 
error, it is quite small due to high value of $K_{P}$. The overshoot is small; however, slight oscillations are present in the output.

$P I$ controller, Ziegler-Nichols tuning method, $K_{P}=171$; $T_{i}=0.75 ; K_{I}=K_{P} / T_{i}=228$. From the analysis of the closed loop system response (see Fig. 12), it results that the PI regulator does not provide a null steady state error. The oscillability of the response in the zone of high rotor speeds is slightly lower, and the overshoot is small.

PI controller, modified Hokushin tuning method, $K_{P}=290 ; T_{i}=0.75 ; K_{I}=K_{P} / T_{i}=386$. In Fig. 13 , the evolution of the output and speed reference is shown. Although the steady state error is not null, it is quite small, given the reduction of the output oscillability. The overshoot is kept at low values and the rise time is similar to that obtained in other cases. Better control system behaviour was observed for all regulators at high rotor speeds.

TABLE V. LOCAL CRITERIA AND CONTROL PERFORMANCE INVERTER WITH ASYNCHRONOUS MOTOR LOAD.

\begin{tabular}{|c|c|c|c|c|}
\hline & $\begin{array}{c}\text { Steady } \\
\text { state } \\
\text { error } \\
\boldsymbol{\varepsilon}_{0 \infty}^{\text {rel }}\end{array}$ & $\begin{array}{c}\text { Position } \\
\text { gain } \\
\boldsymbol{G}_{\boldsymbol{p}}\end{array}$ & $\begin{array}{c}\text { Overshoot } \\
\boldsymbol{\sigma} \%\end{array}$ & $\begin{array}{c}\text { Rise } \\
\text { time } \\
\boldsymbol{t}_{\boldsymbol{c}}(\mathbf{s})\end{array}$ \\
\hline $\begin{array}{c}\text { P controller, } \\
\text { Nichols }\end{array}$ & 0.0242 & 40.3735 & $1.72 \%$ & 0.0264 \\
\hline $\begin{array}{c}\text { PI control law, } \\
\text { Ziegler-Nichols }\end{array}$ & 0.026 & 37.4289 & $5.26 \%$ & 0.0344 \\
\hline $\begin{array}{c}\text { PI controller, } \\
\text { modified } \\
\text { Hokushin }\end{array}$ & 0.0251 & 38.8785 & $4.90 \%$ & 0.0315 \\
\hline
\end{tabular}

TABLE VI. GLOBAL CRITERIA AND CONTROL PERFORMANCE INVERTER WITH ASYNCHRONOUS MOTOR LOAD.

\begin{tabular}{|c|c|c|c|c|}
\hline & ITAE & ISE & IAE & ITSE \\
\hline $\begin{array}{c}\text { P controller, } \\
\text { Nichols }\end{array}$ & 7.2123 & $2.2497 \mathrm{e}+03$ & 14.6313 & 976.5052 \\
\hline $\begin{array}{c}\text { PI control law, } \\
\text { Ziegler-Nichols }\end{array}$ & 7.4271 & 838.5561 & 14.3481 & 403.4566 \\
\hline $\begin{array}{c}\text { PI controller, } \\
\text { modified } \\
\text { Hokushin }\end{array}$ & 6.5038 & 532.7075 & 12.1688 & 280.2413 \\
\hline
\end{tabular}

The analysis of the control performance (local criteria, Table V) shows a surprisingly good behaviour of the $\mathrm{P}$ controller (Nichols tuning). Good performance is also achieved with the PI regulator tuned by a modified Hokushin method (adapted such that a higher value of the proportional gain is chosen).

However, the computed global criteria (Table VI) show that from the point of view of these criteria, PI laws are much better, the ISE and ITSE values for P being very high (they capture the error evolution during its evolution range). It is noted that the PI controller tuned with Hokushin method has the best results of the ITAE, ISE, IAE, and ITSE.

Remark 6. The analysis of the proposed control techniques and of their control performance will be useful to develop a functional model of the multilevel inverter system in the frame of a research project (TISIPRO). Thus, the control techniques designed by using software tools will allow the improvement of several issues of the experimental multilevel inverter system, such as optimal energy operation, automatic and manual operation of the output parameters, control of the starting speed of the motors, protection at maximum/minimum output current, limiting output current, operation in unit power factor, active discharge in the network of the energy recovered in the intermediate circuit, local operator panel (display and keyboard), diagnostic capabilities (self-diagnosis).

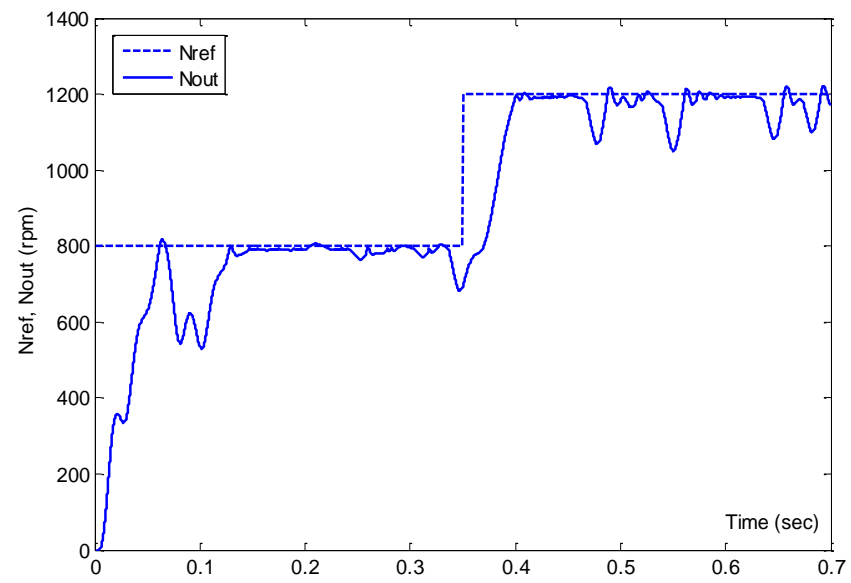

Fig. 11. Prescribed rotational speed and output variable, $\mathrm{P}$ controller, $V / f=$ constant, Nichols tuning method.

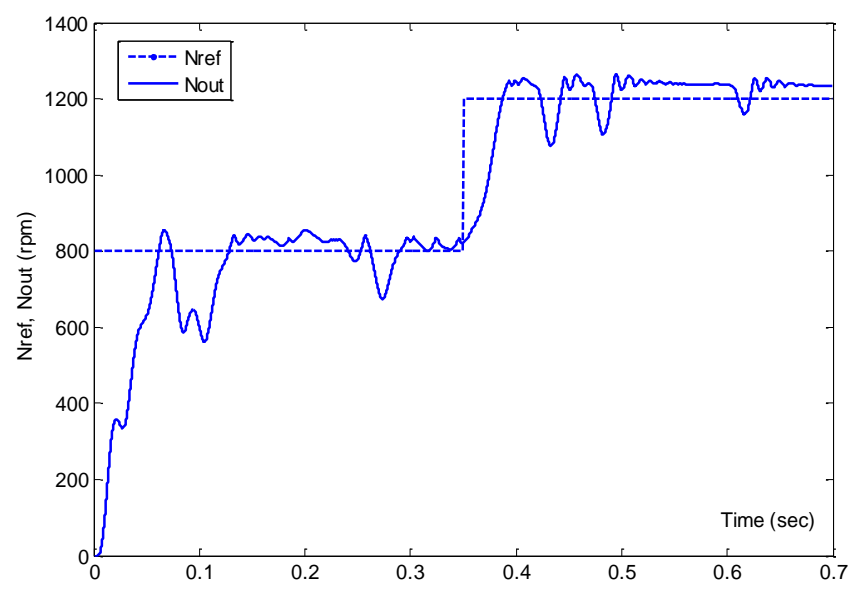

Fig. 12. Output vs. setpoint, PI control law, $V / f=$ constant, Ziegler-Nichols

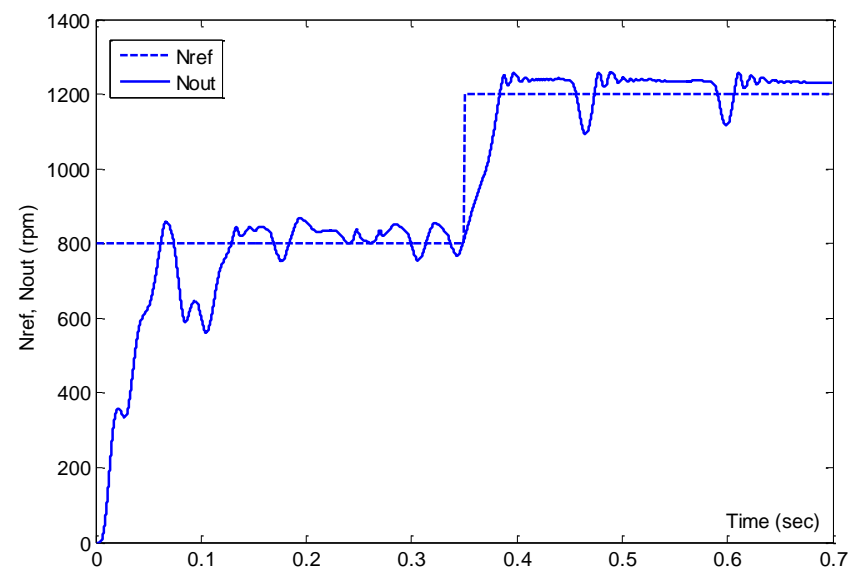

Fig. 13. Profiles of the output and reference, PI controller, $V / f=$ constant, modified Hokushin tuning method.

\section{CONCLUSIONS}

From the numerical analysis of the performance for the control systems implemented for a three-level inverter (with linear load and asynchronous motor load, respectively), several conclusions can be drawn. 
Various integration methods provided by Simulink (ODE45, ODE15s, ODE23s) have been used for the simulation. The best results are obtained with stiff methods (e.g., the modified ODE23s: Rosenbrock), especially in the case of control laws containing the derivative component, where the solver divergence can be more pronounced. A similar code based on the Runge-Kutta-Fehlberg method (RKF45) was used to solve a special differential equation system in [28], [29].

The controllers with better control performance results are generally the PI-type ones for both simulation cases. The derivative control laws do not give adequate results, and a distortion of the fundamental harmonics is observed. The best results for the control system of the inverter in the case of linear load are provided by the PI controllers tuned with Nichols method, both in terms of local and global quality criteria (e.g., steady state error - 0.0021 , rise time $-0.0137 \mathrm{~s}$, ITAE - 0.363). Acceptable performance is also achieved with the Ziegler-Nichols tuned PI controller. The best results for the inverter control system with asynchronous motor load are provided by the PI control law tuned via the modified Hokushin method (e.g., steady state error - 0.0025, rise time $-0.0315 \mathrm{~s}$, ITAE - 6.503). However, from the point of view of local quality criteria, good results were also achieved with the $\mathrm{P}$ controller (Nichols). The simulation considered the saturation introduced into the command, so that the implementation of the control system is realistic. This approach avoids problems related to command deployment when the proportional gain has very high values (which were achieved especially in the speed control system).

The results obtained for the qualitative evolution of the controlled variables, but also for the quality criteria and related control performance, are realistic. Behaviours due to non-linearities and saturations inherently present in closed loop systems leading to the deterioration of "ideal" performance have been observed (e.g., with non-zero null steady state errors although integrative laws are implemented, oscillations). Although the global criteria provide somewhat more complete information on control performance, the local criteria are more common in practice.

Achieving superior performance for closed loop control systems dedicated to three-level inverter control requires the design of more advanced nonlinear control laws, which can ensure an improved control system behaviour.

Further research will also target the experimental tests with the functional three-level inverter characterized by some innovative features.

\section{CONFLICTS OF INTEREST}

The authors declare that they have no conflicts of interest.

\section{REFERENCES}

[1] Y. V. Shevyrev, A. V. Pichuev, and N. Y. Shevyreva, "Improving energy performance in networks with semiconductor converters", in Proc. of 2019 International Conference on Industrial Engineering, Applications and Manufacturing, Sochi, Russia, 2019, pp. 1-6. DOI: 10.1109/ICIEAM.2019.8743020.

[2] A. A. Gebreel, "Survey on topologies, and control techniques for the most common multilevel inverters", International Journal of
Scientific and Engineering Research, vol. 6, no. 6, pp. 345-353, 2015.

[3] R. Maheshwari, S. Munk-Nielsen, and S. Busquets-Monge, "Design of neutral-point voltage controller of a three-level NPC inverter with small DC-link capacitors", IEEE Transactions on Industrial Electronics, vol. 60, no. 5, pp. 1861-1871, 2013. DOI: 10.1109/TIE.2012.2202352.

[4] L. Popova, T. Musikka, R. Juntunen, M. Polikarpova, M. Lohtander, and J. Pyrhönen, "Design and modeling of low-inductive busbars for athree-level ANPC inverter", International Review of Electrical Engineering, vol. 9, no. 1, pp. 7-15, 2014.

[5] IEEE Standard for Requirements, Terminology, and Test Code for Dry-Type Air-Core Series-Connected Reactors, IEEE Std C57.162011 (Revision of IEEE Std C57.16-1996), 2012.

[6] T. A. Meynard and H. Foch, "Multi-level conversion: High voltage choppers and voltage-source-inverters", in Proc. of PESC'92 Record. 23rd Annual IEEE Power Electronics Specialists Conference, 1992, pp. 397-403. DOI: 10.1109/PESC.1992.254717.

[7] J. Wang, B. Yang, J. Zhao, Y. Deng, X. He, and X. Zhixin, "Development of a compact 750KVA three-phase NPC three-level universal inverter module with specifically designed busbar", in Proc. of 2010 25th Annual IEEE Applied Power Electronics Conference and Exposition (APEC), 2010, pp. 1266-1271. DOI: 10.1109/APEC.2010.5433338.

[8] J. Rodriguez, J.-S. Lai, and F. Z. Peng, "Multilevel inverters: A survey of topologies, controls, and applications", IEEE Transactions on Industrial Electronics, vol. 49, no. 4, pp. 724-738, 2002. DOI: 10.1109/TIE.2002.801052.

[9] A. Dekka, B. Wu, V. Yaramasu, R. L. Fuentes, and N. R. Zargari, "Model predictive control of high-power modular multilevel converters-An overview", IEEE Journal on Emerging and Selected Topics in Power Electronics, vol. 7, no. 1, pp. 168-183, 2019. DOI: 10.1109/JESTPE.2018.2880137.

[10] M. P. Kazmierkowski, L. G. Franquelo, J. Rodriguez, M. A. Perez, and J. I. Leon, "High-performance motor drives", IEEE Industrial Electronics Magazine, vol. 5, no. 3, pp. 6-26, 2011. DOI: 10.1109/MIE.2011.942173.

[11] K. J. Åström and T. Hagglund, Automatic Tuning of PID Controllers, 2nd ed. North Carolina, USA: Instrument Society of America, 1995.

[12] K. J. Åström and R. M. Murray, Feedback Systems. An Introduction for Scientists and Engineers. USA: Princeton University Press, 2008. DOI: $10.1515 / 9781400828739$.

[13] C. Marin, Control Structures and Laws (in Romanian). Craiova, Romania: Universitaria Publ. House, 2000.

[14] V. M. Alfaro and R. Vilanova, Model-reference Robust Tuning of PID Controllers. Switzerland: Springer, 2016. DOI: 10.1007/978-3-31928213-8.

[15] A. Nabae, I. Takahashi, and H. Akagi, "A new neutral-point-clamped PWM inverter", IEEE Transactions on Industry Applications, vol. IA17, pp. 518-523, 1981. DOI: 10.1109/TIA.1981.4503992.

[16] Y. Zhang, Z. Zhao, and J. Zhu, "A hybrid PWM applied to highpower three-level inverter-fed induction-motor drives", IEEE Transactions on Industrial Electronics, vol. 58, no. 8, pp. 3409-3420, 2011. DOI: 10.1109/TIE.2010.2090836.

[17] C. Roncero-Clemente, E. Romero-Cadaval, O. Husev, and J. Martins, "New operation strategy for a grid-connected three-phase three-level NPC qZS inverter based on power losses", Elektronika ir Elektrotechnika, vol. 22, no. 3, pp. 60-65, 2016. DOI 10.5755/j01.eie.22.3.15316.

[18] W. Subsingha, "Design and analysis three phase three level diodeclamped grid connected inverter", Energy Procedia, vol. 89, pp. 130 136, 2016. DOI: 10.1016/j.egypro.2016.05.019.

[19] M. Kwokwai, XHP - Flexible High-Power Platform for Optimizing Power Converter Design, Infineon Technologies, Seoul, 11 Sep. 2018. [Online]. Available: https://www.infineon.com/

[20] T. Brückner, S. Bernet, and H. Güldner, "The active NPC converter and its loss-balancing control", IEEE Transactions on Industrial Electronics, vol. 52, no. 3, pp. 855-868, 2005. DOI: 10.1109/TIE.2005.847586.

[21] C. Marin, D. Popescu, E. Petre, and D. Selişteanu, "Modeling and control of the orthogonalization plants in textile industry", IEEE Transactions on Industry Applications, vol. 55, no. 4, pp. 4247-4257, 2019. DOI: 10.1109/TIA.2019.2907893.

[22] B. J. Lurie and P. Enright, Classical Feedback Control: With MATLAB® and Simulink®, 3rd ed. Routledge, CRC Press, 2019.

[23] C. S. Chin, Computer-Aided Control Systems Design: Practical Applications Using MATLAB® and Simulink®. CRC Press, 2017. DOI: $10.1201 / \mathrm{b} 13697$. 
[24] MATLAB User's Guide, The Mathworks Inc., USA, 2014.

[25] MATLAB: The Language of Technical Computing, Release notes, The Math Works Inc., 2015.

[26] Research report RI_3_A2, TISIPRO, Romania: University of Craiova, Indaeltrac, 2020.

[27] D. Topan, L. Mandache, and R. Suesse, Advanced Analysis of Electric Circuits. Wissenschaftsverlag Thüringen, Langenwiesen, 2011.
[28] M. Negrea, I. Petrisor, and B. Weyssow, "On revisited models of L-H transition for tokamak plasmas", Journal of Optoelectronics and Advanced Materials, vol. 10, no. 8, pp. 1946-1949, 2008

[29] M. Negrea, "Diffusion of stochastic magnetic field lines with average poloidal magnetic component", Plasma Physics and Controlled Fusion, vol. 61, no. 6, art. ID 065004, 2019. DOI: 10.1088/13616587/ab105c.

This article is an open access article distributed under the terms and conditions of the Creative Commons Attribution 4.0 (CC BY 4.0) license (http://creativecommons.org/licenses/by/4.0/). 